\title{
Estilos de fé e sentido da vida
}

\author{
Style of faith and meaning of life
}

\author{
Thiago Antonio Avellar de Aquino ${ }^{[a]}$, Cintya Thaiana Arav́jo Cabral Dantas ${ }^{[b]}$, lanny Felinto Medeiros ${ }^{[b]}$, \\ Imytissonara Oliveira A. Leôncio de Moraes ${ }^{[b]}$, Myriam de Oliveira Melo ${ }^{[b]}$, Najara Mirella Cordeiro do Nascimento ${ }^{[c]}$, \\ Samkya Fernandes de 0. Andrade ${ }^{[d]}$, Maria do Socorro Abrantes ${ }^{[e]}$, Vânia Nunes Pires ${ }^{[b]}$
}

\footnotetext{
${ }^{[a]}$ Doutor em Psicologia Social pela Universidade Federal da Paraíba (UFPB), professor do Departamento de Ciências das Religiões da mesma instituição, João Pessoa, PB - Brasil, e-mail: logosvitae@ig.com.br

${ }^{[b]}$ Graduadas em Psicologia pela Universidade Estadual da Paraíba (UEPB), Campina Grande, PB Brasil, e-mails: cintyadantas@ hotmail.com, iannyfelinto@hotmail. com, imytissonara.oliveira@hotmail. com, myrianmelo2@hotmail.com, vanunespires@gmail.com

[c] Psicóloga do Núcleo de Atenção à Saúde da Família (NASF), Mossoró, RN - Brasil, e-mail: psinajara. nascimento@gmail.com
}

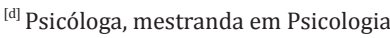
Social pela Universidade Federal da Paraíba (UFPB), João Pessoa, PB Brasil, e-mail:

samkyafernandes@hotmail.com

${ }^{[\mathrm{e}]}$ Psicóloga, atua na linha de pesquisa Saúde mental do adolescente e juventude: comportamentos específicos e procedimentos preventivos no campo da Saúde, na Universidade Estadual da Paraíba (UEPB), Campina Grande, PB Brasil, e-mail: mariabrantescg@hotmail.com

Recebido: 07/12/2010

Received: 12/07/2010

Aprovado: 16/11/2011

Approved: 11/16/2011

\section{Resumo}

0 presente trabalho teve como objetivo identificar os estilos de fé e relacioná-los com os níveis de religiosidade e vazio existencial. Para tanto, utilizou-se como principal referencial teórico a análise existencial de Viktor Frankl, que compreende a religiosidade como uma vontade de sentido último para a vida. A amostra foi constituída por 25 pessoas com idade média de 31 anos. Os instrumentos utilizados foram o Teste Propósito de Vida (PIL-Test), de James C. Crumbauch e Leonard T. Maholick, um questionário de atitude religiosa e seis perguntas da entrevista sobre o desenvolvimento da fé, originalmente elaborada por James W. Fowler. Por meio de análise de conteúdo foi possível identificar categorias pertinentes as concepções de Deus; o que faz a vida significante; crenças, valores e compromissos; momentos de comunhão ou harmonia com Deus ou com o universo; propósito da vida e o que é uma pessoa religiosa. Os resultados foram discutidos a luz da logoterapia e análise existencial de Viktor Frankl.

Palavras-chave: Religiosidade. Análise existencial. Sentido da vida.

\section{Abstract}

The present paper attempts identify the stiles of faith and yours relationships with religiosity and existential emptiness levels. Then, the reference principal was the existential analyses of Viktor Frankl, this theory understand the religiosity as search for ultimate meaning of life. The sample was of 25 participants with mean age of 31 years. The instruments used were Purpose in Life Test of James C. Crumbauch e Leonard T. Maholick, an inventory of religiosity attitude and the interview of the development of faith, of James W. Fowler. The results of the content analyses indicated types of God conceptions, what makes life meaningful; beliefs, values and commitments; moments of communion or harmony with God or the universe, purpose of life and what is a religious person. These results were discussed based on logotherapy and existential analyses of Viktor Frankl.

Keywords: Religiosity. Existential analyses. Meaning of life. 


\section{Introdução}

Muitos pesquisadores apontam a religião e a religiosidade como um aspecto fundamental das sociedades e da estrutura da psique humana (Eliade, 1999; Otto, 2007; Jung, 1961, 1978). Esse fato possivelmente decorre da busca de sentido da existência humana, bem como da consciência da finitude. Seguindo esse pensamento, o presente estudo tratou de uma investigação empírica das concepções de Deus e da fé à luz da logoterapia e análise existencial de Viktor Frankl.

\section{A análise existencial de Viktor Frankl e a busca de sentido}

Segundo Lukas (1990), há um desejo profundamente enraizado na dimensão humana que apenas se satisfaz por meio da realização de sentidos e, se ele for frustrado, o ser humano pode falhar na vida. Frankl (1991) foi o principal teórico do século XX que investigou e descreveu a busca de sentido para a vida.

Conforme esse mesmo autor, o fracasso na busca de sentido pode gerar a sensação de vazio existencial. A etiologia do vazio está direcionada às consequências sofridas pelo homem, pois ele não usa o instinto para dizer o que fazer, nem a tradição, como os homens antigos faziam. Isso resulta em um ser humano conformista, querer o que os outros querem, ou até mesmo totalitarista, fazer o que os outros fazem (Frankl, 1990). As próprias neuroses atuais devem ser atribuídas em muitos casos a tal frustração (Frankl, 1973).

Não obstante, Frankl elenca três tipos de valores em que o ser humano pode encontrar sentidos: os criativos, os vivenciais e os atitudinais (Frankl, 1991). Os criadores fazem referência ao trabalho, que consiste nas atividades desempenhadas no ambiente em que está inserido, ou seja, criando um trabalho ou praticando um ato. Já os valores vivenciais se realizam em momentos vividos de forma pura e intensa, experimentando algo (verdade, beleza) ou alguém. Uma forma de experimentar outro ser humano em sua originalidade é amando, pois o amor é a forma mais eficaz de captar maior profundidade da personalidade humana, isso porque é por meio do amor que o ser humano consegue demonstrar e conscientizar o outro a realizar suas potencialidades (Frankl, 1991).
A terceira categoria é a da atitude, que compreende os valores descobertos diante de um destino trágico e imutável. Frankl demonstra que o sentido também pode ser encontrado no sofrimento, ao encontrá-lo, este passa a não ser visto mais como desespero, e torna-se uma verdadeira realização humana (Frankl, 1973, 1991).

\section{Religiosidade segundo Frankl}

Frankl (1973) afirma que um homem religioso, apoiado na fé, torna a passagem pelo sofrimento mais suportável pela atribuição de um sentido maior, de uma causa para tal sofrimento, ainda que desconhecida. Havendo assim, para o homem religioso, uma crença na existência de uma "providência". Frankl discorda da ideia de que, em certas situações, há uma falta de sentido da vida; antes propõe uma incapacidade de compreensão do sentido em termos racionais, o que esse autor passou a chamar de suprassentido, em outras palavras, uma crença incondicional no sentido da vida, mesmo quando o ser humano se encontre em um destino sofrido (Frankl, 1991). O suprassentido não seria apreensível na instância da razão, mas só poderia ser alcançado por meio da fé.

Segundo a análise existencial de Frankl, a religiosidade seria algo que distinguiria o homem dos outros animais, pois parte-se do princípio de que só o homem poderia temer a Deus. Compreende-se, então, que a religiosidade é uma manifestação exclusivamente humana, e que se constituiria também em um caminho ou recurso para a busca do sentido (Pintos, 2007).

Segundo Frankl, o homem religioso apoia a consciência na instância divina. Já o homem não religioso obedece apenas sua consciência e a considera como última instância. Para esse autor, a religião está muito mais presente no homem do que ele imagina conscientemente, posto que Deus seria o monólogo mais íntimo do homem (Frankl \& Lapide, 2005).

Frankl também reconhece que é muito complexo definir Deus, pois a única forma de se relacionar com Ele é por meio do diálogo. Assim, até os ateus também necessitam dessa conversa interior, entretanto, eles afirmam estarem dialogando com sua própria consciência. Não obstante, a religiosidade do homem atual encontra-se inconsciente, posto que é reprimida pelo mundo cientificista (Frankl \& Lapide, 2005). 
A fé e a ciência se necessitam mutuamente, isso porque uma fé incapaz de se confrontar com a ciência corre o risco de se transformar em "superstição". No entanto, o princípio e o fim, a origem e a consumação de todas as coisas são competências exclusivas da religião. Isso porque é por meio da divergência que se é possível uma visão mais ampla. Dessa forma, apesar de terem segmentos distintos, tanto a religião quanto a ciência buscam o bem-estar do homem (Frankl \& Lapide, 2005).

Até aqui foram delineadas as principais ideias de Frankl sofre a religiosidade. Entretanto, com o intuito de apontar as diferenças entre esse autor e outras abordagens, torna-se necessário contrastar as visões de Frankl com a de Freud e a de Jung, o que será descrito na sessão seguinte.

\section{A religiosidade na perspectiva de Freud e Jung}

Para Freud, tanto a religião como Deus são projeções de necessidades neuróticas, que correspondem a situações infantis relacionadas à segurança e à proteção ou, ainda, correspondem a uma interiorização da imagem do pai (Pintos, 2007). É com essa perspectiva que ele tenta buscar a etiologia de muitos conceitos na obra Totem e tabu (1913-1914).

Nessa obra, Freud apresenta o conceito de religião usando como base as histórias do homem primitivo. Segundo ele, esses homens apresentavam características similares com a dos homens de sua época. Assim, as percepções construídas por meio das artes (entre elas as pinturas rupestres), mitos e contos de fadas serviram para melhor compreender essa relação que existe entre o homem e a religião. Dentre os estudos realizados, Freud não acredita que os homens primitivos poderiam ter qualquer tipo de religião na qual adorassem os seres superiores, além de, naquela época, não existir nem um tipo de instituição religiosa (Freud, 1974a).

Assim, a religião para Freud estará ligada ao complexo paterno, o desamparo e a necessidade de proteção do homem, que ele especifica em Totem e tabu (1913-1914). Em o futuro de uma ilusão (1974b), Freud explica que a noção de desamparo inicia na criança, e que esta se ligará a objetos que lhe assegurem proteção e segurança. Dessa forma, a mãe que satisfaz as suas necessidades de fome e de segurança se torna o seu primeiro objeto de proteção, mas logo ela é substituída pelo pai, mais forte, que assume tal posição pelo resto da infância. Posteriormente, tal atitude para com o pai é modificada, devido ao sentimento peculiar de ambivalência, em que ela tanto o teme quanto o anseia e admira. De acordo com Freud, tal sentimento de ambivalência talvez seja pelo relacionamento anterior que a criança teve com a mãe. Sendo assim, o indivíduo cresce e descobre que irá sempre precisar de proteção contra "estranhos poderes superiores", e cria para si deuses nos quais busca proteção, mas também os teme. Os deuses seriam, então, a substituição da figura materna e paterna de proteção.

Já para Jung, Deus é um "arquétipo universal", um conjunto de ideias e imagens inseridas no inconsciente coletivo (Pintos, 2007). Tanto para Freud como para Jung a religiosidade é essencialmente instintiva, em que um "inconsciente religioso" determinaria uma pessoa. Jung dá aspectos psicofísicos na definição de arquétipos, quando afirma que está de alguma forma ligada ao cérebro.

A religião, segundo Jung, é vista como aquilo que Rudolf Otto (2007) chamou de numinosum, que significa dizer que é um efeito ativo ou uma existência não causada por um ato arbitrário. Pelo contrário, o efeito domina o ser humano. 0 numinoso pode ser considerado como a influência de uma presença invisível ou pode ser propriedade de um objeto visível, que produziu um efeito distinto na consciência do indivíduo. E todas as religiões se engajam nessa definição, até mesmo as mais primitivas. Então, pode-se dizer que o termo "religião" é a atitude de uma consciência alterada pela experiência do numinoso (Jung, 1978).

A religião é uma das formas de expressões universais mais antigas da alma humana, podendo ser considerada como uma atitude instintiva. É evidente sua função de manter o equilíbrio psíquico do indivíduo, porque a religião nada mais é que uma subordinação dos fatos irracionais da experiência, não se referindo somente às condições sociais e físicas, e torna-se um assunto importante para muitos indivíduos (Jung, 1961, 1978).

Jung encara a religião como uma "atitude do espírito humano", e que esta palavra propaga uma relação subjetiva com certos fatores extramundanos e metafísicos. 0 propósito e o sentido das religiões permanecem na relação do indivíduo para com Deus (cristianismo, judaísmo, islamismo) ou no caminho da libertação e da salvação (budismo). As religiões pregam uma doutrina de dependência 
do homem com relação a Deus, tendo uma ação tão sugadora quanto à do mundo sobre ele (Jung, 1961, 1978). E quanto às figuras simbólicas das religiões, elas representam a expressão da atitude moral e espiritual específicas. Portanto, a religião pode ser considerada como uma relação com "valor supremo ou mais poderoso", podendo ser positiva ou negativa, voluntária ou involuntária (Jung, 1978).

\section{Críticas de Frankl a Freud e a Jung}

Em se tratando de religião, Frankl considera que a teoria freudiana apresenta Deus como a imagem do pai e a religião como uma neurose da sociedade, degradando-a aos olhos dos pacientes e bloqueando a porta de entrada no supra-humano. Para a logoterapia, embora a religião seja um objeto de estudo, ela é um objeto de sumo interesse, pois todo passo dado pelo paciente religioso possui uma dimensão autêntica e genuína (Frankl, 1973).

Freud considera o aparelho psíquico "como algo" cuja intenção consiste em liquidar e dominar as quantidades de estímulos e magnitudes de excitação que vêm do exterior e interior. No entanto, Frankl contrapõe essa postura argumentando que, visto por esse ângulo, faltaria a característica de autotranscendência da existência no ser humano, que o interesse principal do homem não é por condições internas dele próprio, prazer ou equilíbrio, mas, ele é orientado para o mundo lá fora em busca de um sentido que pudesse realizar ou uma pessoa que pudesse amar (Frankl, 1992).

Com relação a Jung, Frankl aponta que este autor desloca a religiosidade inconsciente para o id, nesse caso, o "eu" não é responsável pelos elementos religiosos; o religioso não pertence à responsabilidade e decisão do "eu", ou seja, não é o ser humano quem se decide por Deus, ficando claro que Jung não considera o homem autônomo em relação à religião. Em vista disso, Frankl faz uma crítica ao reducionismo junguiano, por tratar os fenômenos humanos como expressões de forças impulsivas. Dessa forma, pode-se falar de impulsos religiosos da mesma maneira que nos referimos a um impulso sexual ou agressivo.

No que se refere a Deus, Jung o vê como um arquétipo universal, isto é, uma série de imagens, crenças e ideais que se inserem no nosso inconsciente coletivo, sendo assim, o tema da imagem tem uma grande importância na psicologia junguiana, sendo vista como imago, termo usado para diferenciar a realidade objetiva da percepção subjetiva (Frankl, 1992; Pintos, 2007). Tendo em vista as considerações teóricas mencionadas, considera-se pertinente investigar empiricamente o fenômeno da religiosidade. Assim, a presente pesquisa teve por objetivo identificar a relação entre os estilos de fé e as concepções de Deus com os níveis de percepção do sentido de vida e de religiosidade.

\section{Método}

\section{Participantes}

Foram entrevistadas 25 pessoas da cidade de Campina Grande - PB, sendo 15 do sexo feminino. A média de idade foi de 31 anos, com amplitude de 20 a 45 anos. Com relação à atribuição religiosa, oito se diziam protestantes, 12 católicos, dois espíritas, dois sem religião e um judeu. No que se refere ao grau de escolaridade, 14 eram universitários; quatro possuíam curso superior completo; três estavam cursando o Ensino Fundamental, enquanto um possuía tal instrução; duas pessoas tinham o Ensino Médio completo e uma estava cursando.

\section{Instrumentos para coleta de dados}

O Teste de Propósito de Vida (Pil-Test-R) foi originalmente elaborado por James C. Crumbaugh e Leonard T. Maholich (1964) e revisado por Harlow, Newcomb e Bentler (1987). Essa versão apresenta três fatores: desespero existencial (alfa de Cronbach de 0,69), realização existencial (alfa de Cronbach de 0,71) e vazio existencial (alfa de Cronbach foi 0,72) (Aquino et al., 2009). Esse instrumento tem como finalidade medir o nível de realização de sentido e o vazio existencial, e consiste em 12 itens dispostos em uma escala de avaliação de sete pontos, com os extremos: 1 = discordo totalmente e 7 = concordo totalmente. Os itens dessa escala contemplam os seguintes aspectos: propósito na vida (sete itens, ex.: tenho na vida metas e objetivos muito claros); satisfação com a própria vida (seis itens, ex.: se a vida é rotineira, dolorosa, excitante, triste); liberdade (três itens, ex.: eu não sou uma pessoa muito responsável); medo da morte (um item, ex.: quanto à morte, estou preparado e sem medo); ideias suicidas (um item, ex.: quanto 
ao suicídio, tenho pensado seriamente ao seu respeito como uma saída); se a vida vale a pena (um item, ex.: se eu morresse hoje, sentiria que minha vida foi muito valiosa). Apesar de a escala ser constituída por três fatores, pode ser utilizada como uma estrutura unifatorial.

Escala de atitude religiosa: este instrumento é composto por 20 itens distribuídos de acordo com os componentes da atitude - afetivo-comportamental e cognitivo. Os itens estão dispostos em uma escala intervalar com os seguintes valores: 1 = nunca; 2 = raramente; 3 = às vezes; $4=$ frequentemente; $5=$ sempre. 0 estudo de Diniz e Aquino (2009) indicou uma estrutura unifatorial com a consistência interna alta (alfa de Cronbach $=0,94$ ).

Entrevista sobre o desenvolvimento da fé: esta entrevista foi originalmente elaborada por James W. Fowler (Fowler, Streib, \& Keller, 2004) e tem por objetivo avaliar os estágios da fé dos indivíduos. Esse instrumento é constituído por 25 questões, que estão subdivididas em quatro partes: trama de vida ou revisão de vida; relacionamentos; valores e compromissos atuais; religião. Não obstante, para a presente pesquisa, foram utilizadas apenas seis perguntas do referido instrumento: (1) Como sua imagem de Deus e sua relação com Deus mudaram durante os capítulos de sua vida? Quem ou o que é Deus para você agora?; (2) Você sente que sua vida tem sentido atualmente? 0 que faz a vida significante para você?; (3) Existem quaisquer crenças, valores ou compromissos que parecem ser importantes para sua vida neste momento?; (4) Quando ou onde você se acha mais em comunhão ou harmonia com Deus ou com o universo? Você pensa que a vida humana tem um propósito? Em caso afirmativo, qual você acha que é?; (5) Há um plano para nossas vidas, ou nós somos afetados por um poder ou poderes além de nosso controle?; (6) Você se considera uma pessoa religiosa? 0 que significa isto pra você?

Variáveis sociodemográficas: constitui-se de questões como idade, sexo, escolaridade, estado civil, número de filhos, religião, o quanto uma pessoa se sente religiosa, o que a pessoa faz a maior parte do tempo, se o sujeito é aposentado, pensionista e profissão.

\section{Procedimentos éticos}

Inicialmente, a presente pesquisa foi submetida e aprovada no Comitê de Ética da Universidade Estadual da Paraíba (UEPB), sob o protocolo n. 0519.0.133.000-09. Seguiu todas as diretrizes e normas que regulamentam as pesquisas que envolvem seres humanos, como prescreve a Resolução n. 196/96, do Conselho Nacional de Saúde. Todos os participantes leram e assinaram o Termo de Consentimento Livre e Esclarecido (TCLE) antes de participar da pesquisa em foco.

\section{Procedimentos para coleta de dados}

A entrevista foi realizada de forma individual, em lugares públicos junto à população em geral. 0 respondente era abordado e convidado a participar da pesquisa, se aceitasse, era conduzido a um local mais reservado para responder aos instrumentos. Os participantes receberam a informação de que as respostas dadas seriam confidenciais e analisadas em seu conjunto. Os pesquisadores utilizaram gravações em áudio para as perguntas abertas e, posteriormente, executaram a transcrição na íntegra. 0 tempo médio para responder a todos os instrumentos foi de 30 minutos.

\section{Procedimentos para análise dos dados}

Os dados foram tabulados no Pacote Estatístico para Ciências Humanas (SPSS) e foram realizadas análises descritivas, tais como frequências e o teste $t$ de Student. No que se refere ao material qualitativo, realizou-se inicialmente uma pré-análise por meio de uma leitura flutuante das entrevistas. Em seguida, foi feita uma análise temática, que, segundo Rey (2005), é uma forma de penetrar nas estruturas simbólicas que configuram a vida cotidiana das pessoas em contextos reais. Para tanto, seguiu-se as recomendações de Bardin (2002) para identificar núcleos comuns de sentido no discurso dos participantes, o que, posteriormente, foi agrupado em categorias. Os pesquisadores tiveram também a função de juízes, e as categorias foram extraídas por consenso. No Quadro 1 são explanadas as categorias emergentes dos discursos dos participantes. 
Quadro 1 - Categorias emergentes dos discursos dos participantes

(Continua)

\begin{tabular}{|c|c|c|}
\hline Pergunta & Categoria & Definição \\
\hline \multirow{6}{*}{$\begin{array}{l}\text { Quem ou o que } \\
\text { é Deus? }\end{array}$} & $\begin{array}{l}\text { Definição pelos } \\
\text { atributos divinos }\end{array}$ & $\begin{array}{l}\text { Corresponde às atribuições direcionadas a Deus como "ser supremo", "infini- } \\
\text { to", "soberano". }\end{array}$ \\
\hline & Definição como direção & $\begin{array}{l}\text { Corresponde às respostas que atribuem a Deus como sendo uma direção, um } \\
\text { "guia". }\end{array}$ \\
\hline & $\begin{array}{l}\text { Definição como relação/relacio- } \\
\text { namento de amizade }\end{array}$ & $\begin{array}{l}\text { Corresponde à definição da relação com Deus como uma "relação de amiza- } \\
\text { de", uma relação em que Deus sempre "está ao seu lado". }\end{array}$ \\
\hline & Definição como tudo & Corresponde às respostas onde Deus foi determinado como "tudo". \\
\hline & $\begin{array}{l}\text { Definição como princípio } \\
\text { propulsor "ajuda a superar as } \\
\text { dificuldades". }\end{array}$ & $\begin{array}{l}\text { Corresponde às respostas que designam Deus como sendo o ser que "dá } \\
\text { forças", "encoraja", "cria", "ajuda a superar as dificuldades". }\end{array}$ \\
\hline & Sem conteúdo & Corresponde às respostas incoerentes. \\
\hline \multirow{8}{*}{$\begin{array}{l}\text { O que faz a vida } \\
\text { significante? }\end{array}$} & Deus & $\begin{array}{l}\text { Corresponde às respostas nas quais Deus é colocado como Aquele em que } \\
\text { é depositada uma fé, e que essa fé estimula a capacidade de enfrentar os } \\
\text { problemas, o dia a dia, "superar tudo". }\end{array}$ \\
\hline & Relacionamentos & $\begin{array}{l}\text { Corresponde às respostas que colocam as relações familiares, de amizades, } \\
\text { amorosas, como sendo de fundamental importância e que são expostas como } \\
\text { o sentido de sua vida. }\end{array}$ \\
\hline & Ajudar o próximo & $\begin{array}{l}\text { Corresponde às respostas em que a satisfação se dá à medida que se ajuda o } \\
\text { outro, sair de si para ir ao encontro do outro. }\end{array}$ \\
\hline & Projetar o futuro & $\begin{array}{l}\text { Corresponde às respostas em que a vida faz sentido porque a ela são coloca- } \\
\text { dos objetivos para o futuro, e o fato de querer conquistá-los e alcançá-los é o } \\
\text { que proporciona o sentido. }\end{array}$ \\
\hline & Bem-estar & $\begin{array}{l}\text { Corresponde às respostas em que o fato de se ter saúde, tanto fisicamente } \\
\text { como psiquicamente, "feliz consigo mesmo", já permite um sentido de vida. }\end{array}$ \\
\hline & Estar vivo & $\begin{array}{l}\text { Corresponde às respostas que atribuem o sentido de vida ao fato de se ter } \\
\text { mais uma oportunidade "de acordar e ter mais um dia de vida", "todo dia é } \\
\text { dia de renovação". }\end{array}$ \\
\hline & Realização profissional & $\begin{array}{l}\text { Corresponde às respostas em que o sucesso no trabalho ou nos estudos com- } \\
\text { pleta o seu sentido de vida. }\end{array}$ \\
\hline & Tudo & Corresponde às respostas em que "tudo" na vida faz sentido. \\
\hline \multirow{7}{*}{$\begin{array}{l}\text { Crenças, } \\
\text { valores ou com- } \\
\text { promissos são } \\
\text { importantes } \\
\text { para a vida? }\end{array}$} & Fé & Corresponde às religiões, “fé em Deus”, “salvação”, “crença em Deus”, “Deus”. \\
\hline & Relacionamentos & $\begin{array}{l}\text { Corresponde aos compromissos e valores atribuídos à família, amigos e } \\
\text { outros. }\end{array}$ \\
\hline & Relação profissional vida & $\begin{array}{l}\text { Corresponde às respostas em que o trabalho e os estudos foram colocados } \\
\text { como compromissos importantes para sua vida. }\end{array}$ \\
\hline & Nenhuma & $\begin{array}{l}\text { Corresponde à resposta de que não existia nenhuma crença, valor ou com- } \\
\text { promisso importante. }\end{array}$ \\
\hline & Religião & Corresponde aos "valores cristãos" e à religião. \\
\hline & Valores morais & Corresponde às respostas que envolvem respeito, altruísmo, amor. \\
\hline & Sem conteúdo & Corresponde às respostas incoerentes. \\
\hline
\end{tabular}


Quadro 1 - Categorias emergentes dos discursos dos participantes

(Conclusão)

\begin{tabular}{|c|c|c|}
\hline Pergunta & Categoria & Definição \\
\hline \multirow{9}{*}{$\begin{array}{l}\text { Quando ou } \\
\text { onde você se } \\
\text { acha mais em } \\
\text { comunhão ou } \\
\text { em harmonia } \\
\text { com Deus ou } \\
\text { com o univer- } \\
\text { so? }\end{array}$} & Em oração & Corresponde às respostas em que o ato de orar aproxima-se de Deus. \\
\hline & Na igreja & $\begin{array}{l}\text { Corresponde às respostas em que nesse local pode-se encontrar comunhão } \\
\text { com Deus. }\end{array}$ \\
\hline & Sozinho & $\begin{array}{l}\text { Corresponde às respostas em que "estar sozinho" significa estar em comu- } \\
\text { nhão ou em harmonia com Deus ou com o universo. }\end{array}$ \\
\hline & No lar & $\begin{array}{l}\text { A "casa" é apontada como o local onde se pode alcançar essa comunhão ou } \\
\text { harmonia. }\end{array}$ \\
\hline & $\begin{array}{l}\text { Em contato com a naturezao } \\
\text { universo }\end{array}$ & $\begin{array}{l}\text { Corresponde às respostas em que a natureza permite estabelecer uma comu- } \\
\text { nhão ou harmonia com Deus e com o universo. }\end{array}$ \\
\hline & $\begin{array}{l}\text { Todo momento e em todo luga- } \\
\text { rou a comunhão }\end{array}$ & $\begin{array}{l}\text { Corresponde às respostas em que generalizaram e colocaram todos os luga- } \\
\text { res para encontrar a harmonia ou a comunhão. }\end{array}$ \\
\hline & Antes de dormirharmonia. & $\begin{array}{l}\text { Corresponde às respostas em que a hora antes de dormir é o momento em } \\
\text { que se pode encontrar a comunhão ou a harmonia. }\end{array}$ \\
\hline & Ouvindo música & $\begin{array}{l}\text { Corresponde à resposta em que o ato de ouvir música permite encontrar essa } \\
\text { comunhão. }\end{array}$ \\
\hline & $\begin{array}{l}\text { Quando cumpro a vontade de } \\
\text { Deus }\end{array}$ & $\begin{array}{l}\text { Corresponde às respostas em que foi ressaltada a vontade de cumprir o } \\
\text { que Deus preconiza, na medida em que "agrada a Deus" pode se sentir em } \\
\text { comunhão com Ele. }\end{array}$ \\
\hline \multirow{6}{*}{$\begin{array}{l}\text { Qual é o propó- } \\
\text { sito da vida? }\end{array}$} & Exaltar a Deus & $\begin{array}{l}\text { Corresponde às respostas em que Deus é colocado como o "que tem poder } \\
\text { sobre as vidas" e a exaltação faz parte desse propósito, como "amar a Deus } \\
\text { sobre todas as coisas". }\end{array}$ \\
\hline & Busca pessoal & $\begin{array}{l}\text { Corresponde às respostas em que cada um "segue" e "constrói" o seu propó- } \\
\text { sito. }\end{array}$ \\
\hline & Promoção dos propósitos & $\begin{array}{l}\text { Corresponde às respostas em que o propósito da vida é "render adoração a } \\
\text { Deus e obedecer a seus preceitos". }\end{array}$ \\
\hline & Ajudar o próximo & Corresponde às respostas em que ajudar ao próximo faz parte da "missão". \\
\hline & Realização pessoal & $\begin{array}{l}\text { Corresponde às respostas em que o viver bem, consigo e com o outro, faz com } \\
\text { que se tenha um propósito. }\end{array}$ \\
\hline & Sem conteúdo & Corresponde às respostas incoerentes. \\
\hline \multirow{7}{*}{$\begin{array}{l}\text { O que significa } \\
\text { ser uma pessoa } \\
\text { religiosa? }\end{array}$} & Ter uma crença/religião & $\begin{array}{l}\text { Corresponde às respostas que indicam que uma pessoa, para ser religiosa, } \\
\text { precisa ter uma crença ou religião. }\end{array}$ \\
\hline & Relacionar-se com Deus & É ter esse contato com o "ser supremo", "estar mais perto de Deus". \\
\hline & Fazer o bem & $\begin{array}{l}\text { Corresponde às respostas em que as "pessoas que fazem o bem são conside- } \\
\text { radas religiosas". }\end{array}$ \\
\hline & Realizar atividades espirituais & $\begin{array}{l}\text { Corresponde às respostas em que os atos de orar, fazer uma leitura bíblica e } \\
\text { participar de rituais classificam uma pessoa como sendo religiosa. }\end{array}$ \\
\hline & Ter fé & $\begin{array}{l}\text { Corresponde às respostas em que, para ser considerada uma pessoa religiosa, } \\
\text { deve-se ter fé, "crer em alguma coisa". }\end{array}$ \\
\hline & Seguir os ensinamentos bíblicos & $\begin{array}{l}\text { Corresponde às respostas nas quais são consideradas pessoas religiosas as } \\
\text { que seguem os preceitos cristãos ou "instruções bíblicas". }\end{array}$ \\
\hline & Tudo & $\begin{array}{l}\text { Corresponde à resposta em que a palavra "tudo" está relacionada a um perío- } \\
\text { do de mudança experimentado pelo entrevistado. }\end{array}$ \\
\hline
\end{tabular}

Fonte: Dados da pesquisa. 


\section{Resultados}

No que se refere à perspectiva quantitativa do trabalho, observou-se que a média de religiosidade da amostra investigada foi de 68,2 (DP $=14,6$ ), tendo uma amplitude de 26 a 96 pontos. Já o nível médio de vazio existencial foi de 23,2 (DP = 5,8), com uma amplitude de 14 a 36 pontos. Quanto à análise qualitativa, na Tabela 1 é possível observar as categorias que emergiram por meio das respostas ao inventário de James Fowler (Fowler et al., 2004).

Tabela 1 - Categorias e frequências das respostas à pergunta: "Quem ou 0 que é Deus para você agora?"

\begin{tabular}{|lcc|}
\hline Nome das categorias & $\begin{array}{c}\text { FI } \\
\text { (Frequência } \\
\text { absoluta) }\end{array}$ & $\begin{array}{c}\text { Fr\% } \\
\text { (Frequência } \\
\text { relativa) }\end{array}$ \\
\hline Tudo & 11 & $44 \%$ \\
\hline Atributos divinos & 9 & $36 \%$ \\
\hline Direção & 6 & $24 \%$ \\
\hline $\begin{array}{l}\text { Relacionamento de } \\
\text { amizade }\end{array}$ & 5 & $20 \%$ \\
\hline Princípio propulsor & 4 & $16 \%$ \\
\hline Sem conteúdo & 1 & $4 \%$ \\
\hline
\end{tabular}

Fonte: Dados da pesquisa.

De acordo com a Tabela 1, pode-se observar que a definição de Deus para a amostra pesquisada foi diversificada, porém, houve a predominância da designação de Deus como Tudo (44\%). Tal resultado é verificado por meio dos seguintes recortes: "Deus é tudo pra mim"; "Deus é tudo até agora... pra mim ele é tudo". Além dessa, outra resposta significativa foi a que traz a definição de Deus como Atributos divinos (36\%): "Deus pra mim é um ser acima de tudo e de todos..." e "Eu toda vida acreditei que é um ser supremo". Dentre as outras respostas estão as definições de Deus como Direção (24\%), por exemplo: "Deus hoje para mim é um guia". Em seguida, algumas respostas definem Deus pelo Relacionamento de amizade (20\%): "Hoje tenho uma relação de amizade com Deus"; e como Princípio propulsor (16\%): "É ele que move, que dá esperança". Respostas sem conteúdo foram apresentadas por $4 \%$ dos entrevistados.
Na Tabela 2, observa-se que a maioria das pessoas que compõem a amostra refere-se aos Relacionamentos (60\%) como o que faz a vida significante para elas: "A vontade que eu tenho de viver, de ajudar os outros, de estar com minha família"; "Meus filhos, a felicidade dos meus filhos, isso para mim é o mais importante". Outras respostas foram verificadas, como: Realização profissional (32\%): "Meu trabalho profissional é também algo que faço com intenso prazer"; "[...] estar empregada e não desempregada". Também foram observadas respostas com relação ao Projetar o futuro (24\%): "[...] porque eu tenho uma visão de futuro"; "Acho que a perspectiva do futuro também dá significado à vida". Com relação à categoria Deus (20\%), observa-se as seguintes respostas: "A fé em Deus supera tudo, né?"; "Eu tenho um Deus muito forte dentro de mim, então tudo, tudo vale a pena". Na categoria Ajudar ao próximo (16\%), verifica-se os seguintes discursos: " $A$ vontade que eu tenho de viver, de ajudar os outros"; "A possibilidade de estar me formando, terminando um curso e poder ajudar outras pessoas, faz com que a minha vida tenha sentido". Em Bem-estar (16\%), encontram-se falas como: "Enquanto eu tiver saúde, né?, paz [...]"; "É porque hoje eu vivo bem, tenho saúde, graças a Deus". Na categoria Estar vivo (16\%), há os seguintes discursos: "É acordar todo dia e estar aí vivendo"; "Eu acho que só você ter condições de acordar". E, por fim, na categoria Tudo (8\%), as seguintes falas:

Tabela 2 - Categorias e frequências das respostas à pergunta: "0 que faz a vida significante para você?"

\begin{tabular}{|lcc}
\hline Nomes das categorias & $\begin{array}{c}\text { FI } \\
\text { (Frequência } \\
\text { absoluta) }\end{array}$ & $\begin{array}{c}\text { Fr\% } \\
\text { (Frequência } \\
\text { relativa) }\end{array}$ \\
\hline Relacionamentos & 15 & $60 \%$ \\
\hline Realização profissional & 8 & $32 \%$ \\
\hline Projetar o futuro & 6 & $24 \%$ \\
\hline Deus & 5 & $20 \%$ \\
\hline Ajuda ao próximo & 4 & $16 \%$ \\
\hline Bem-estar & 4 & $16 \%$ \\
\hline Estar vivo & 4 & $16 \%$ \\
\hline Tudo & 2 & $8 \%$ \\
\hline
\end{tabular}

Fonte: Dados da pesquisa. 
"Tudo, tudo..."; "Tudo, quando eu me levanto e olho as nuvens".

Em relação às crenças, valores e compromissos, é possível observar na Tabela 3 maior incidência de respostas direcionadas à $F e ́(48 \%)$, indicada nos seguintes recortes: "Crença, a fé, a fé sempre, a fé"; "A reza, a fé". Outras respostas apresentadas foram categorizadas como Relacionamentos pessoais (28\%), com as seguintes falas: "Meus compromissos com a minha casa, com meu trabalho, com meus filhos"; "Meus filhos, minha família, minha vida". Com o mesmo percentual, nos Relacionamentos profissionais encontra-se o seguinte exemplo: "Compromissos, os próprios que eu tenho com a universidade, acho extremamente importante para minha vida, o que estou tendo com meu curso, com a minha futura profissão, esse compromisso tem relevância muito grande". Nos Valores morais (16\%) observam-se as seguintes falas: "Amor e respeito"; "Valores, o de... é... tentar ajudar o próximo e não tentar interferir no bem-estar do outro...". E, quanto à Religião (8\%), constatou-se as seguintes afirmações: "Sim, a religião..."; "Todos os valores cristãos que eu tenho são importantes". Também foram encontradas respostas categorizadas como Sem conteúdo (8\%) e Nenhuma (4\%).

Como se pode observar na Tabela 4, os entrevistados relataram que se acham mais em comunhão, harmonia com Deus ou com o universo Em todos os momentos e em todos os lugares (36\%). 0 que confirma esse dado é o tipo de discurso que se segue:

Tabela 3 - Categorias e frequências das respostas à pergunta: "Existem quaisquer crenças, valores, ou compromissos que parecem ser importantes pra sua vida neste momento?"

\begin{tabular}{|lcc}
\hline Nome das categorias & $\begin{array}{c}\text { FI } \\
\text { (Frequência } \\
\text { absoluta) }\end{array}$ & $\begin{array}{c}\text { Fr\% } \\
\text { (Frequência } \\
\text { relativa) }\end{array}$ \\
\hline Fé & 12 & $48 \%$ \\
\hline Relacionamentos & 7 & $28 \%$ \\
\hline Relação profissional & 7 & $28 \%$ \\
\hline Valores morais & 4 & $16 \%$ \\
\hline Religião & 2 & $8 \%$ \\
\hline Sem conteúdo & 2 & $8 \%$ \\
\hline Nenhuma & 1 & $4 \%$ \\
\hline
\end{tabular}

Fonte: Dados da pesquisa.
"Todo momento"; "Todo local". Além dessa resposta, a referida questão apresenta outras como Na igreja (24\%), exemplificada por: "Ir pra Igreja porque lá eu me sinto bem..."; "Todo local, mas, mais ainda na Igreja". Em relação à categoria Sozinho(a) (24\%), pode ser ilustrada por meio dos seguintes exemplos: "Quando estou sozinho"; "Quando estou só, quando eu ligo os louvores". A categoria Lar (20\%) constata-se por meio das respostas: "Principalmente quando estou em casa..."; "No meu lar...". Na categoria Em contato com a natureza (16\%), são encontradas as falas: "Acho que sentado na areia da praia, no fim da tarde com uma lua bem linda"; "Ah! Quando estou em uma praia...". Em Antes de dormir (12\%) percebe-se as seguintes falas: "Acho que é no final do dia. Quando você vai dormir". Na categoria Em oração (8\%), há os exemplos: "Nos momentos de oração."; "Numa prece também...", e em Quando cumpre a vontade de Deus (8\%): "Quando eu faço aquilo que Deus predisse, então é amar a Deus sobre qualquer coisa". Em Ouvindo música (4\%): "Quando estou ouvindo música".

Constatou-se que $100 \%$ das pessoas entrevistadas acreditam que a vida humana tem um propósito. Pode-se observar na Tabela 5, que, dentre os propósitos identificados por elas, o que mais se destaca é a Busca pessoal (28\%): "Caberá ao ser humano

Tabela 4 - Categorias e frequências das respostas à pergunta: "Quando ou onde você se acha mais em comunhão ou harmonia com Deus ou com o universo?"

\begin{tabular}{|lcc|}
\hline Nome das categorias & $\begin{array}{c}\text { FI } \\
\text { (Frequência } \\
\text { absoluta) }\end{array}$ & $\begin{array}{c}\text { Fr\% } \\
\text { (Frequência } \\
\text { relativa) }\end{array}$ \\
\hline $\begin{array}{l}\text { Em todo momento e em } \\
\text { todo lugar }\end{array}$ & 9 & $36 \%$ \\
\hline Na igreja & 6 & $24 \%$ \\
\hline Sozinho(a) & 6 & $24 \%$ \\
\hline No lar & 5 & $20 \%$ \\
\hline $\begin{array}{l}\text { Em contato com a } \\
\text { natureza }\end{array}$ & 4 & $16 \%$ \\
\hline Antes de dormir & 3 & $12 \%$ \\
\hline Em oração & 2 & $8 \%$ \\
\hline $\begin{array}{l}\text { Quando cumpre a von- } \\
\text { tade de Deus }\end{array}$ & 1 & $4 \%$ \\
\hline Ouvindo música & & \\
\hline
\end{tabular}

Fonte: Dados da pesquisa. 
procurar esse propósito de vida, em minha opinião é isso". Na sequência, as respostas com caráter mais significativo foram as que se referiram à Exaltação $a$ Deus (24\%): “Adoração a Deus, que é nosso criador, a ele devemos tudo que somos". Ajudar o próximo aparece em $20 \%$ das pessoas entrevistadas, como pode ser verificado neste recorte: "Nós viemos pra ajudar o outro". Também foram verificadas respostas que se enquadram em Realização pessoal (16\%), como: "Acho que a vida humana existe para você viver". Em relação às respostas acerca da Promoção dos propósitos de Deus (12\%), pode-se observar: "Promover os propósitos de Deus". Foram categorizadas como Sem conteúdo $4 \%$ das respostas.

Quando indagados acerca da existência de planos ou poderes maiores, se estes os atingem ou não, $80 \%$ dos respondentes disseram que sim, 12\% disseram que não e $4 \%$ ficaram na categoria $\mathrm{Sem}$ conteúdo.

Com relação à pergunta "Você se considera uma pessoa religiosa?", 76\% dos entrevistados disseram que sim, $20 \%$ disseram que não e $4 \%$ responderam de forma intermediária. Como sugere a Tabela 6 , ao questionar as pessoas sobre o que isso significava para elas, obteve-se as seguintes respostas: $40 \%$ dos entrevistados responderam Ter uma crença/religião, como "ser religiosa é seguir uma religião [...] sigo os preceitos de Deus, então, acredito que sou religiosa"; $24 \%$ enfatizaram o Relacionar-se com Deus,

Tabela 5 - Categorias e frequências das respostas à pergunta: "Você pensa que a vida humana tem um propósito? Em caso afirmativo, qual você acha que é? Há um plano para nossas vidas, ou nós somos afetados por um poder ou poderes além de nosso controle?"

\begin{tabular}{|lcc}
\hline $\begin{array}{l}\text { Nome das catego- } \\
\text { rias }\end{array}$ & $\begin{array}{c}\text { FI } \\
\text { (Frequência } \\
\text { absoluta) }\end{array}$ & $\begin{array}{c}\text { Fr\% } \\
\text { (Frequência } \\
\text { relativa) }\end{array}$ \\
\hline Busca pessoal & 7 & $28 \%$ \\
\hline Exaltar a Deus & 6 & $24 \%$ \\
\hline Ajudar ao próximo & 5 & $20 \%$ \\
\hline Realização pessoal & 4 & $16 \%$ \\
\hline $\begin{array}{l}\text { Promoção dos pro- } \\
\text { pósitos de Deus }\end{array}$ & 3 & $12 \%$ \\
\hline Sem conteúdo & 1 & $4 \%$ \\
\hline
\end{tabular}

Fonte: Dados da pesquisa. observado neste recorte: "pra mim ser religiosa é você ter um contato pleno e bonito, seja lá com qual intensidade for, mas que você tenha esse contato com o ser supremo, com Deus". Em Fazer o bem (16\%), pode ser observado: "[...] e fazer o bem sempre, eu acho que não há religião sem caridade". As respostas que correspondem à categoria Ter fé também apresentaram 16\%, exemplificadas em: "Tem que crer em alguma coisa e uma das coisas mais certas a se apegar é a fé". A categoria Seguir os ensinamentos bíblicos também apresentou a mesma porcentagem de 16\%, como em: "Acredito e sigo as instruções bíblicas para uma vida de comunhão com o Pai". A categoria Realizar atividades espirituais (12\%) é visivelmente observada neste recorte: "Ser religioso pra mim é estar em oração".

Após a realização da análise de conteúdo, foi possível explorar quais categorias se associam com o nível de religiosidade e vazio existencial. Por meio de um teste $t$ de Student, verificou-se que as pessoas que definem Deus por seus atributos divinos apresentam um escore médio menor na escala de atitude religiosa ( $M=60,9)$ em comparação com aqueles que não apresentaram a mesma categoria $(\mathrm{M}=$ $72,5)$ em seus discursos, $t(21,7)=2,20, p<0,05$. Já as pessoas que definem Deus como Tudo apresentou as maiores médias na pontuação da escala de atitude religiosa $(M=76,8)$ do que as pessoas

Tabela 6 - Categorias e frequências das respostas para a pergunta: "Você se considera uma pessoa religiosa? 0 que significa isso para você?"

\begin{tabular}{lcc}
\hline Nome das categorias & $\begin{array}{c}\text { FI } \\
\text { (Frequência } \\
\text { absoluta) }\end{array}$ & $\begin{array}{c}\text { Fr\% } \\
\text { (Frequência } \\
\text { relativa) }\end{array}$ \\
\hline Ter uma crença/religião & 10 & $40 \%$ \\
\hline Relacionar-se com Deus & 6 & $24 \%$ \\
\hline Fazer o bem & 4 & $16 \%$ \\
Ter fé & 4 & $16 \%$ \\
\hline $\begin{array}{l}\text { Seguir os ensinamentos } \\
\text { bíblicos }\end{array}$ & 4 & $16 \%$ \\
Realizar atividades & 3 & $12 \%$ \\
espirituais & 1 & $4 \%$ \\
\hline Tudo & & \\
\hline
\end{tabular}

Fonte: Dados da pesquisa. 
que não apresentaram esse significado ( $M=61,4)$, $\mathrm{t}(3,1)=23, \mathrm{p}<0,01$. Por outro lado, as pessoas que concebem Deus como amigo $(\mathrm{M}=17,4)$ apresentam menor grau de vazio existencial do que aquelas que não o fazem $(\mathrm{M}=24,6), \mathrm{t}(23)=2,84, \mathrm{p}<0,01$.

Na pergunta sobre qual seria o propósito da vida humana, o teste $t$ indicou que as médias no nível de religiosidade se diferenciaram nas categorias ajuda ao próximo e exaltar a Deus. Assim, as pessoas que apresentaram em seus discursos a categoria ajuda ao próximo obtiveram médias superiores na escala de atitude religiosa $(\mathrm{M}=84,3)$ quando comparadas com aquelas que não apresentaram esse conteúdo em suas respostas ( $M=65,1), t(23)=2,7, p<0,01$. Por sua vez, aquelas pessoas que concebem que o propósito da vida humana seria exaltar a Deus também apresentam médias maiores $(M=80,0)$ do que aquelas que não apresentam esse conteúdo na escala de atitude religiosa $(M=64,4), t(23)=2,52, p<0,01$.

\section{Discussão}

O objetivo da pesquisa foi identificar a relação entre os estilos de fé e as concepções de Deus com os níveis de percepção do sentido de vida e de religiosidade. Considera-se que ele foi plenamente alcançado, tendo em vista os resultados anteriormente apresentados. Entretanto, ressalta-se que os resultados não são passíveis de generalização, tendo em vista as limitações da amostra investigada.

Com relação aos resultados qualitativos, permitiram identificar os diversos estilos de fé e religiosidade dos entrevistados. Dois estilos chamam especial atenção: o estilo racional, que define Deus por seus atributos, e o estilo vivencial, que o define como relacionamento. Nesse sentido, Frankl concebe um relacionamento do homo religiosus com um "Tu" transcendente. Deus também foi definido pelos participantes da pesquisa por meio da categoria $d i-$ reção, ou seja, a tradução da palavra logos. Destarte, para o homem religioso, se há um sentido na existência humana também deve haver um provedor de sentido, ou um suprassentido.

Com relação à pergunta $O$ que faz a vida significante pra você, observa-se que as respostas, de forma geral, relacionam-se à perspectiva da autotranscedência. Segundo Frankl (1991), por meio da autocompreensão ontológica pré-reflexiva, o ser humano interpreta a vida sempre em função de algo ou alguém que não ele mesmo. Nesse caso, relacionamentos estariam vinculados aos valores vivenciais, enquanto que a profissão estaria relacionada aos valores criativos.

De forma mais específica, os valores da amostra estudada emergiram na ocasião da pergunta: Existem quaisquer crenças, valores, ou compromissos que parecem ser importantes pra sua vida nesse momento? As respostas indicaram os seguintes temas: fé, relacionamentos, relação profissional e valores morais. Frankl (1973) concebe que o homem não se satisfaz em estar no mundo, mas ele procura motivos e razões para viver. Nessa perspectiva, as respostas sugerem que as crenças e valores dos participantes da pesquisa constituem-se como sentidos e valores para atuar no mundo.

Em outra pergunta - Quando ou onde você se acha mais em comunhão ou harmonia com Deus ou com o universo? - Foi possível identificar a necessidade de algumas pessoas em ter um momento de solidão e recolhimento. Segundo Frankl (1978), para que o ser humano possa escutar a sua consciência, torna-se necessário alguns momentos de solilóquios, o que seria para o homem religioso seu diálogo interior. Assim, os resultados sugerem que para o homo religiosus o estar em comunhão com Deus ou com o universo é estar em lugares sagrados como a Igreja, em uma relação dialógica com a oração ou no cumprimento de uma vontade divina. Frankl (1992) compreende que a religiosidade só é genuína quando é existencial, quando a própria pessoa decide por ela, e que estamos caminhando para uma religiosidade profundamente pessoal e cada pessoa poderá encontrar sua linguagem própria para dirigir-se a Deus.

Outro estilo de resposta foi a de que a harmonia pode ser alcançada pelos valores de vivência, como ouvir música e entrar em contato com a natureza. Por meio das entrevistas percebeu-se que todos os entrevistados sentem-se em sintonia com Deus em algum momento ou lugar. Esse aspecto corrobora com o pensamento de Frankl (1990), quando concebe que a religiosidade pode ser vivenciada de forma consciente ou inconsciente e percebida no relacionamento com um Deus pessoal, sendo este imanente no ser humano (Frankl, 1992).

Outra questão investigada foi se a vida humana possui um propósito. Frankl concebe que a 
motivação primária do ser humano é a vontade de sentido, em consonância com essa perspectiva todos os respondentes afirmaram que a vida tem um propósito. Mas, quando indagados sobre qual seria o propósito da vida, os mesmos atribuíram as seguintes concepções: exaltar a deus, busca pessoal, promoção dos propósitos e ajudar o próximo. Frankl (1990) concebe que a meta da existência humana é a autotranscendência, pois o ser humano não seria uma mônada, mas um ser aberto para o mundo. Assim, as respostas estão em consonância com essa visão, na medida em que indicaram algo no mundo pelo qual a pessoa deve viver. Por meio da escala de atitude religiosa, pôde-se perceber que as pessoas mais religiosas concebem que o propósito da vida seria ajudar o próximo e exaltar a Deus.

Nesta pesquisa foi possível identificar que as pessoas que pontuam mais em uma escala de atitude religiosa tendem a definir Deus como "tudo", e aquelas que definem Deus por seus atributos têm menor pontuação nessa mesma escala. Dessa maneira, pode-se conceber que, para a pessoa religiosa, a sua relação com Deus não seria impessoal, ou mesmo racional e distante de sua existência. 0 que se confirma quando a resposta Deus como amigo sugeriu menor grau de vazio existencial na pontuação do Pil-test. Isso pode ser bem compreendido quando Frankl (1992) constata um efeito colateral da religiosidade na "cura da alma", embora a função primária da religião seja a "salvação da alma". Dessa forma, parece plausível conceber que a pessoa religiosa encontra um sentido na vivência pessoal com um Deus quando este é percebido como um ser enraizado em sua existência.

\section{Considerações finais}

A presente pesquisa tentou demonstrar a riqueza e a amplitude dos estudos voltados para a questão da fé e suas relações com o sentido da vida, corroborando, de forma empírica, as preocupações ontológicas com questões metafísicas ainda presentes na sociedade atual. 0 estudo também permitiu mapear a subjetividade das pessoas religiosas e identificar qual o estilo de fé que se associa negativamente ao vazio existencial. À guisa de conclusão, considera-se que a vontade de um sentido último pode ser concebida como uma categoria imanente, e que a forma de expressar essa vontade está relacionada com a situação existencial de cada pessoa, cabendo ao ser humano ler na sua própria existência o anelo por um sentido transcendente.

\section{Referências}

Aquino, T. A. A., Correia, A. P. M., Marques, A. L. C., De Souza, C. G., Freitas, H. C. A., Araújo, I. F., Dias, P. S., \& Araújo, W. F. (2009). Atitude religiosa e sentido da vida: Um estudo correlacional. Psicologia Ciência e Profissão, 29(2), 228-243.

Bardin, L. (2002). Análise de conteúdo (L. A. Reto \& A. Pinheiro, Trad.). Lisboa: Edições 70.

Diniz, A. C., Aquino, T. A. A. (2009). A relação da religiosidade com as visões de morte. Religare, 6(2), 90-105.

Eliade, M. (1999). O sagrado e o profano: A essência das religiões. São Paulo: Editora Martins Fontes.

Fowler, J. W., Streib, H., \& Keller, B. (2004). Manual for faith development research. (3. ed.). Bielefeld: Research Center for Biographical Studies in Contemporary Religion; Bielefeld; Center for Research in Faith and Moral Development; Emory University.

Frankl, V. E. (1992). A presença ignorada de Deus. São Leopoldo: Editora Sinodal; Petrópolis: Editora Vozes.

Frankl, V. E. (1990). A questão do sentido em psicoterapia. São Paulo: Pafins.

Frankl, V. E. (1991). Em busca de sentido. 2. Ed. São Leopoldo: Sinodal; Petrópolis: Vozes.

Frankl, V. E. (1978). Fundamentos antropológicos da psicoterapia. Rio de Janeiro: Zahar.

Frankl, V. E. (1973). Psicoterapia e sentido de vida. São Paulo: E.G.R.T.

Frankl, V. E., Lapide, P. (2005). Búsqueda de Dios y sentido de la vida. Diálogo entre un teólogo y un psicólogo. Barcelona: Editorial Herder.

Freud, S., (1974a). Totem e tabu. In: Freud, S. Edição standard brasileira das obras psicológicas completas de Sigmund Freud (Vol.13, pp.11-191). Rio de Janeiro: Imago. (Originalmente publicado em 1913)

Freud, S. (1974b). 0 futuro de uma ilusão. In: Freud, S. Edição standard brasileira das obras psicológicas completas de Sigmund Freud (Vol. 21). Rio de Janeiro: Imago. (Originalmente publicado em 1927) 